\title{
High Body Mass Index and Use of Fentanyl Iontophoretic Transdermal System in Postoperative Pain Management: Results of a Pooled Analysis of Six Phase 3/3B Trials
}

Eugene R. Viscusi · Li Ding · J. Bradley Phipps · Loretta M. Itri •

Philip R. Schauer

Received: October 14, 2016 / Published online: December 21, 2016

(C) The Author(s) 2016. This article is published with open access at Springerlink.com

\section{ABSTRACT}

Introduction: Postoperative pain management can be challenging in patients with a high body mass index (BMI) especially as a result of poor venous access and delayed ambulation that can result in serious complications. Fentanyl iontophoretic transdermal system (ITS) is a needle-free, patient-controlled analgesic method available for use in acute postoperative pain. The primary objective of these analyses was to determine if there were any differences between patients with high BMI $\left(>40 \mathrm{~kg} / \mathrm{m}^{2}\right)$ and lower BMIs $\left(<30 \mathrm{~kg} / \mathrm{m}^{2}\right.$ and $35-40 \mathrm{~kg} / \mathrm{m}^{2}$ ) in terms of efficacy or safety.

Enhanced content To view enhanced content for this article go to http://www.medengine.com/Redeem/ B337F06049744C3E.

E. R. Viscusi

Thomas Jefferson University, 111 South 11th Street, Gibbon Building, Suite 8490, Philadelphia, PA

19107, USA

\section{Ding · L. M. Itri $(\bowtie)$}

The Medicines Company, Parsippany, NJ, USA

e-mail: loretta.itri@themedco.com

J. B. Phipps

The Medicines Company, Redwood City, CA, USA

P. R. Schauer

Cleveland Clinic, Cleveland, $\mathrm{OH}$, USA
Methods: Data from three registration, placebo-controlled trials and three active-comparator trials using fentanyl ITS (IONSYS $^{\circledR}$, The Medicines Company, Parsippany, NJ) for the management of postoperative pain were analyzed using BMI categories of $<35 \mathrm{~kg} / \mathrm{m}^{2}, 35-40 \mathrm{~kg} / \mathrm{m}^{2}$, and $>40 \mathrm{~kg} / \mathrm{m}^{2}$. The majority of patients had lower abdominal or orthopedic surgery. For these analyses, the primary efficacy variables were assessed via patient global assessment of pain control (PGA) at $24 \mathrm{~h}$ and investigator global assessment (IGA) at study discharge. PGA and IGA are categorical 4-point scales (excellent, good, fair, or poor) with treatment "success" defined as either excellent or good. Safety was evaluated via treatment emergent adverse events (TEAEs).

Results: There were 1403 patients randomly assigned and treated with fentanyl ITS for at least $3 \mathrm{~h}$ (BMI $<35 \mathrm{~kg} / \mathrm{m}^{2}$ : 1180; 35-40 kg/m²: 136, BMI $>40 \mathrm{~kg} / \mathrm{m}^{2}: 85$; and 2 missing). PGA treatment success, which evaluates the method of pain control, at $24 \mathrm{~h}$ was consistent in the high and low BMI groups in patients treated with fentanyl ITS $\left(<35 \mathrm{~kg} / \mathrm{m}^{2}: \quad 946 / 1180\right.$ [80.2\%]; 35-40 kg/m²: 103/136 [75.7\%]; and 
$>40 \mathrm{~kg} / \mathrm{m}^{2}: 65 / 85$ [76.5\%]). The IGA results at study discharge were similar to the PGA. Safety appeared similar with fentanyl ITS across the BMI groups.

Conclusion: In these analyses, fentanyl ITS was as efficacious, as assessed by the PGA ratings of treatment "success", in patients with high BMI $\left(>40 \mathrm{~kg} / \mathrm{m}^{2}\right)$ as it was for those with lower BMIs $\left(<35 \mathrm{~kg} / \mathrm{m}^{2}\right.$ or $\left.35-40 \mathrm{~kg} / \mathrm{m}^{2}\right)$ and was generally well tolerated across all BMI categories.

Keywords: Fentanyl; High body mass index; Ionsys; Iontophoretic transdermal system; Obesity; Patient-controlled analgesia; Postoperative pain

\section{INTRODUCTION}

Almost one-third of adults in the USA are obese (body mass index [BMI] of $30 \mathrm{~kg} / \mathrm{m}^{2}$ or greater) [1]. Worldwide obesity has doubled since 1980 [2], and more patients who are obese are undergoing bariatric surgery as a method for weight control. Patients with a BMI greater than $40 \mathrm{~kg} / \mathrm{m}^{2}$ or a BMI between $35 \mathrm{~kg} / \mathrm{m}^{2}$ and $40 \mathrm{~kg} /$ $\mathrm{m}^{2}$ with co-morbid conditions are potential candidates for bariatric surgery. In addition, obesity is associated with other co-morbid chronic medical conditions such as orthopedic, cardiac, and pulmonary disease that make these patients more challenging to manage postoperatively. In these obese patients especially, successful postoperative pain management is critical with dual goals of reducing or eliminating pain and regaining mobility as quickly as possible [3]. Opioids continue to be the mainstay of most postoperative multimodal therapy. However, appropriate concern about adverse events such as respiratory depression or oversedation in patients with obesity and challenges with venous access may lead to undertreatment of pain.

Fentanyl iontophoretic transdermal system (ITS) IONSYS $^{\circledR}$, The Medicines Company, Parsippany, New Jersey) is a pre-programmed, needle-free drug delivery system used to deliver patient-controlled analgesia (PCA) for acute postoperative pain in adult patients during hospitalization. Fentanyl is administered via iontophoresis which is a transdermal delivery of fentanyl through the skin via the application of a low-intensity electrical field [4]. Fentanyl ITS delivers doses based on patient demand. Unlike traditional PCA, no venous access or intravenous (IV) lines are needed to apply or administer the fentanyl ITS system. Given the increasing number of obese patients as well as the increasing number of surgical procedures being performed in this population, it is important to evaluate the relative efficacy and safety of fentanyl ITS in the obese population. The existing phase 3 dataset provides an initial opportunity to explore these questions. The primary purpose of these analyses was to determine if there were any differences between patients with high BMI and lower BMIs in terms of efficacy or safety. A secondary outcome was to compare fentanyl ITS versus morphine IV PCA to evaluate if the efficacy profile was similar between the two treatments by BMI category.

\section{METHODS}

Trials were included in these analyses if they studied the fentanyl iontophoretic transdermal system in prospective randomized controlled trials and also included BMI. A literature search resulted in five unique clinical trials that are included in these analyses [5-9]. One additional study was not included as BMI data was not 
available [10]. The manufacturer provided details for this analysis on a 6th phase 3 trial that has not been published. This represents all of the phase $3 / 3 \mathrm{~B}$ trials conducted utilizing fentanyl ITS. The details of each trial are presented in Table 1.

In all studies, patients admitted to the postanesthesia care unit after major surgery were titrated to comfort with opioids prior to receiving study drug. All studies utilized the validated patient global assessment of the method of pain control (PGA) [11]. The PGA is a categorical 4-point scale (excellent, good, fair, or poor) with treatment success defined as excellent or good. The PGA was the primary outcome of the four active-comparator phase $3 \mathrm{~B}$ trials. The PGA is rated by the patient directly and does not reflect the treating clinician or investigator's assessment. While the PGA was not designed as a patient-reported outcome instrument, it is a patient-reported instrument to assess the method of pain control. In the validation paper the authors concluded that "The PGA of the method of pain control is an informative and useful measure for assessing pain control provided by different drug delivery systems for patients experiencing postoperative pain." The studies also utilized the investigator global assessment of the method of pain control (IGA). The IGA is a similar categorical 4-point scale to the PGA with treatment success defined as excellent or good. Safety was assessed via treatment-emergent adverse events (TEAEs). For purposes of these analyses, the following subgroups were utilized: $<35 \mathrm{~kg} / \mathrm{m}^{2}, 35-40 \mathrm{~kg} /$ $\mathrm{m}^{2}$, and $>40 \mathrm{~kg} / \mathrm{m}^{2}$. These group definitions were selected on the basis of indication prerequisites for bariatric surgery which currently includes a BMI of at least $40 \mathrm{~kg} / \mathrm{m}^{2}$ or a BMI of $35 \mathrm{~kg} / \mathrm{m}^{2}$ or more with a serious health problem linked to obesity [12]. Five of the six studies have been previously published with full methodology [5-9]. The sixth study was a placebo-controlled trial similar in design to the other two placebo-controlled trials. The primary purpose of these analyses was to determine if there were any differences between patients with high BMI and lower BMIs in terms of efficacy or safety. A secondary purpose was to evaluate if there were any differences between patients treated with fentanyl ITS versus morphine IV PCA across the BMI categories.

\section{Compliance with Ethics Guidelines}

All studies received applicable institutional review board approval prior to initiation. All patients who had participated in the studies provided written informed consent prior to study enrollment. All procedures performed were in accordance with the ethical standards of the institutional and/or national research committee and with the 1964 Declaration of Helsinki, as revised in 2013.

\section{Statistical Analysis}

The evaluable efficacy population included patients who had at least $3 \mathrm{~h}$ of study treatment, consistent with the analyses for the original phase 3 trials. The safety population included all patients who received any study treatment, also referred to as the treated population.

Descriptive statistics were utilized for most variables, including the analysis of PGA, IGA, and safety. A meta-analysis was conducted on the secondary outcomes comparing fentanyl ITS with morphine IV PCA for the PGA and IGA and was performed according to the Cochrane methodology [13]. The meta-analysis was conducted using random effects models [13], with fixed effect models being explored as 


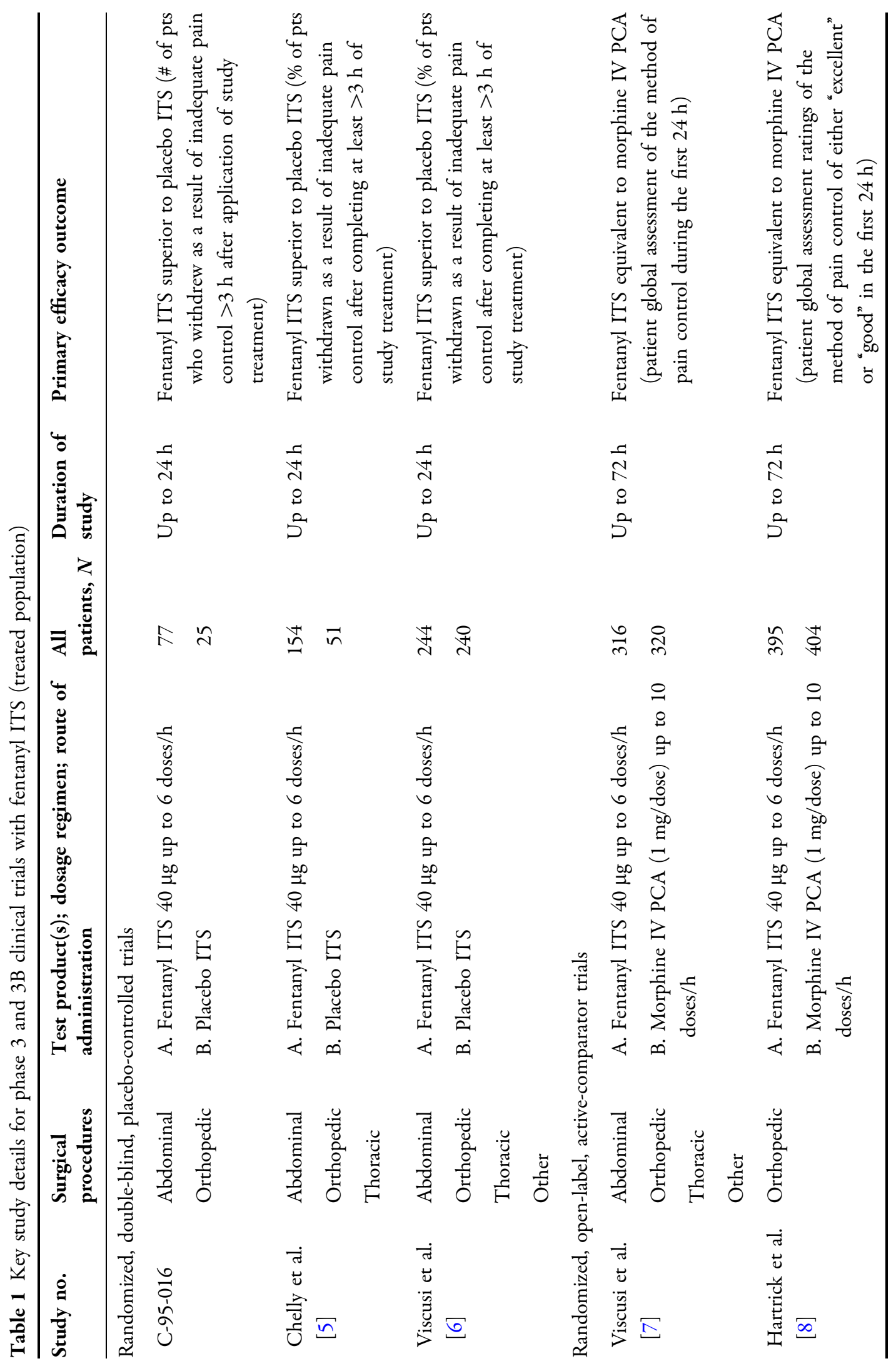




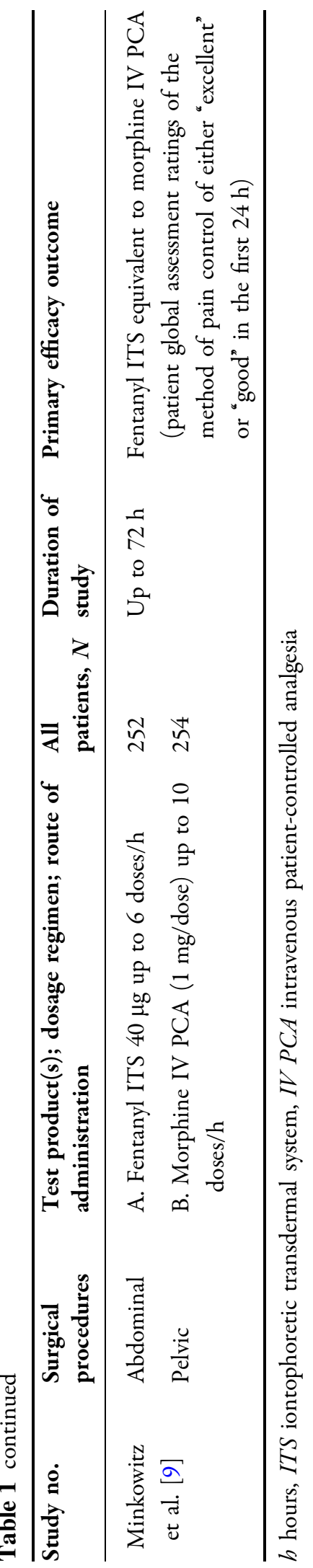

secondary analyses. For dichotomous variables, odds ratios (ORs) indicating the probability of the outcome occurring were calculated. Statistical tests were performed at the 0.05 significance level, with no multiplicity adjustments. Ninety-five percent confidence intervals (CIs) were provided for all parameters.

Only patients with observations at the given time points were included in the calculations. Any missing values were excluded from analyses.

\section{RESULTS}

In the controlled studies included in these analyses there were a total of 1436 patients randomized to fentanyl ITS. There were 1212 who had BMIs $<35 \mathrm{~kg} / \mathrm{m}^{2}, 138$ who had a BMI $\geq 35 \mathrm{~kg} / \mathrm{m}^{2}$ and $\leq 40 \mathrm{~kg} / \mathrm{m}^{2}$, and 86 who had a $\mathrm{BMI}>40 \mathrm{~kg} / \mathrm{m}^{2}$. In the placebo-controlled trials there were 316 patients randomized to placebo. Of these, there were 271 who had BMIs $<35 \mathrm{~kg} /$ $\mathrm{m}^{2}, 30$ who had a BMI $>35 \mathrm{~kg} / \mathrm{m}^{2}$ and $\leq 40 \mathrm{~kg} /$ $\mathrm{m}^{2}$, and 15 who had a BMI $>40 \mathrm{~kg} / \mathrm{m}^{2}$. In the active-comparator trials there were 977 patients randomized to morphine IV PCA. Of these, there were 802 who had BMIs $<35 \mathrm{~kg} / \mathrm{m}^{2}, 112$ who had a $\mathrm{BMI}>35 \mathrm{~kg} / \mathrm{m}^{2}$ and $\leq 40 \mathrm{~kg} / \mathrm{m}^{2}$, and 63 who had a BMI $>40 \mathrm{~kg} / \mathrm{m}^{2}$. The demographic and baseline characteristics across the BMI categories for fentanyl ITS, morphine IV PCA, and placebo are presented in Table 2. The majority of patients were female and white. The groups were similar across all treatments and BMI categories; however, there were fewer patients in the $>40 \mathrm{~kg} / \mathrm{m}^{2}$ group who underwent orthopedic surgery compared to the other two BMI categories.

The mean number of fentanyl ITS doses used in the first $24 \mathrm{~h}$ across the BMI categories was 32 doses in patients with BMI $<35 \mathrm{~kg} / \mathrm{m}^{2}, 30$ doses 


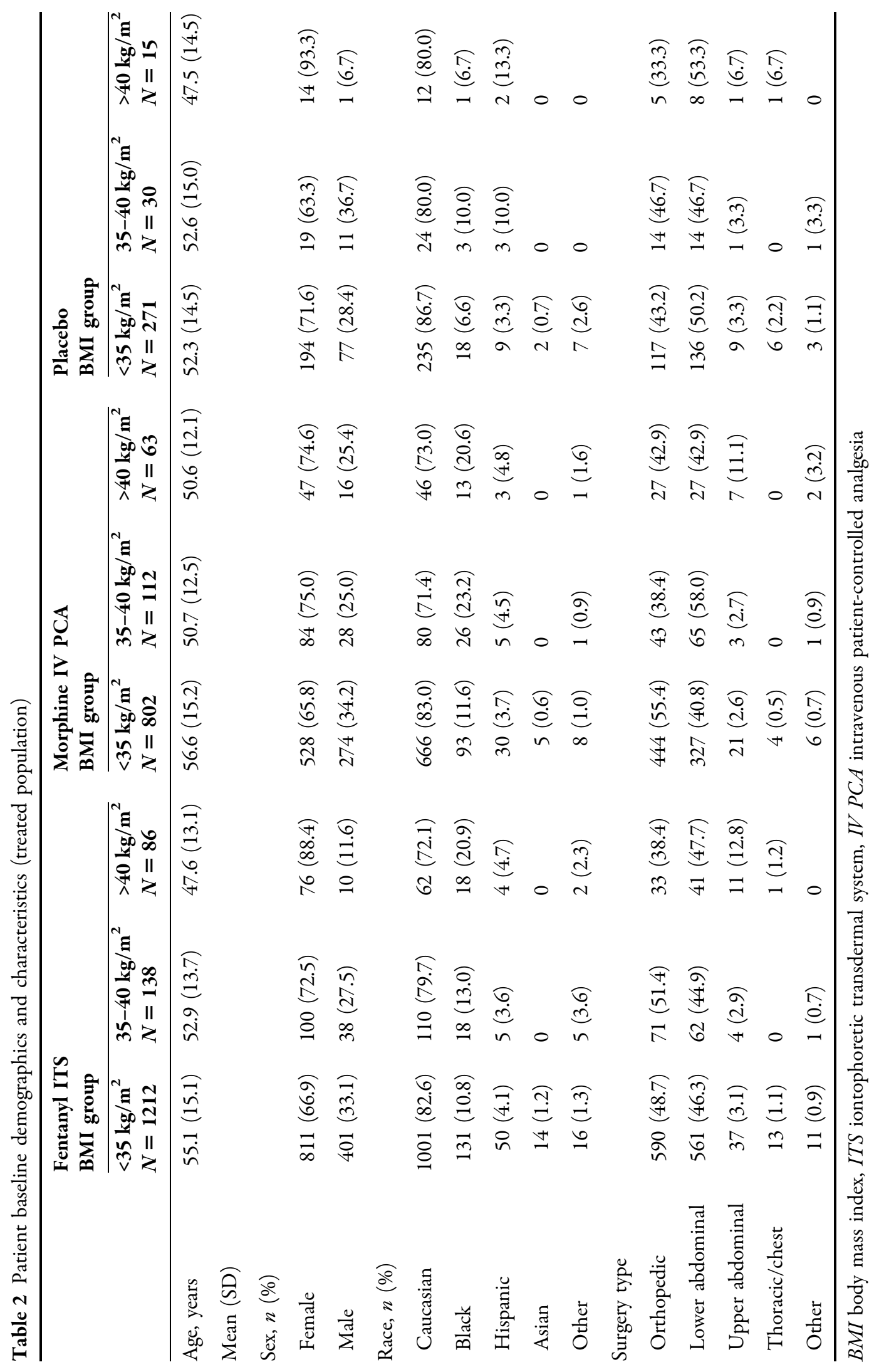


Table 3 Global assessments by BMI category (evaluable population)

\begin{tabular}{|c|c|c|c|}
\hline & \multicolumn{3}{|l|}{$\begin{array}{l}\text { Fentanyl ITS } \\
\text { BMI group }\end{array}$} \\
\hline & $\begin{array}{l}\mathrm{BMI}<35 \mathrm{~kg} / \mathrm{m}^{2} \\
N=1180 \\
n(\%)\end{array}$ & $\begin{array}{l}\text { BMI } 35-40 \mathrm{~kg} / \mathrm{m}^{2} \\
N=136 \\
n(\%)\end{array}$ & $\begin{array}{l}\text { BMI }>40 \mathrm{~kg} / \mathrm{m}^{2} \\
N=85 \\
n(\%)\end{array}$ \\
\hline \multicolumn{4}{|c|}{ Patient global assessment at $24 \mathrm{~h}$} \\
\hline Success & $946(80.2)$ & $103(75.7)$ & $65(76.5)$ \\
\hline Excellent & $564(47.8)$ & $57(41.9)$ & $42(49.4)$ \\
\hline \multicolumn{4}{|c|}{ Investigator global assessment at last assessment } \\
\hline Success & $988(83.7)$ & $106(77.9)$ & $62(72.9)$ \\
\hline Excellent & $691(58.6)$ & $66(48.5)$ & $50(58.8)$ \\
\hline
\end{tabular}

The patient global assessment of the method of pain control and the investigator global assessment of the method of pain control are categorical 4-point scales (excellent, good, fair, or poor) with treatment "success" defined as ratings of either excellent or good

$B M I$ body mass index, ITS iontophoretic transdermal system, IV PCA intravenous patient-controlled analgesia

in patients with $\mathrm{BMI} \geq 35 \mathrm{~kg} / \mathrm{m}^{2}$ and $\leq 40 \mathrm{~kg} / \mathrm{m}^{2}$, and 32 doses in patients with BMI $>40 \mathrm{~kg} / \mathrm{m}^{2}$. The mean number of doses of morphine IV PCA used in the first $24 \mathrm{~h}$ across the BMI categories was 39 doses in patients with BMI $<35 \mathrm{~kg} / \mathrm{m}^{2}$, 46 doses in patients with $\mathrm{BMI} \geq 35 \mathrm{~kg} / \mathrm{m}^{2}$ and $\leq 40 \mathrm{~kg} / \mathrm{m}^{2}$, and 40 doses in patients with BMI $>40 \mathrm{~kg} / \mathrm{m}^{2}$. The mean number of doses of placebo ITS used in the first $24 \mathrm{~h}$ across the BMI categories was 24 doses in patients with BMI $<35 \mathrm{~kg} / \mathrm{m}^{2}, 19$ doses in patients with BMI $\geq 35 \mathrm{~kg} / \mathrm{m}^{2}$ and $\leq 40 \mathrm{~kg} / \mathrm{m}^{2}$, and 30 doses in patients with $\mathrm{BMI}>40 \mathrm{~kg} / \mathrm{m}^{2}$.

The magnitude of treatment "success" on the PGA at $24 \mathrm{~h}$ was similar in the high BMI groups and the low BMI group in patients treated with fentanyl ITS $\left(<35 \mathrm{~kg} / \mathrm{m}^{2}\right.$ : 946/1180 [80.2\%]; 35-40 kg/m²: 103/136 [75.7\%]; and $>40 \mathrm{~kg} / \mathrm{m}^{2}: 65 / 85$ [76.5\%]) (Table 3). Similarly, the magnitude of patients rating their method of treatment as "excellent" at $24 \mathrm{~h}$ on the PGA was consistent across the high and low BMI groups (Table 3). The IGA results at study discharge were similar between BMI categories for either treatment "success" or rating of "excellent" (Table 3).

Analyzing the active-comparator trials, the proportion of patients with treatment "success" or rated as "excellent" on the PGA was comparable between fentanyl ITS and morphine IV PCA for the high and low BMI categories (Fig. 1a, b). Similarly, treatment "success" or ratings of "excellent" according to the IGA was comparable between fentanyl ITS and morphine IV PCA across high and low BMI categories (Fig. 1c, d).

The most common TEAEs were nausea, pyrexia, vomiting, headache, and application site erythema across all of the BMI categories in the patients randomized and treated with fentanyl ITS (Table 4). There were a similar number of patients in the morphine IV PCA group who experienced these same AEs; however, pyrexia was seen in more morphine IV PCA patients than in fentanyl ITS patients and application site erythema was unique to fentanyl ITS. 

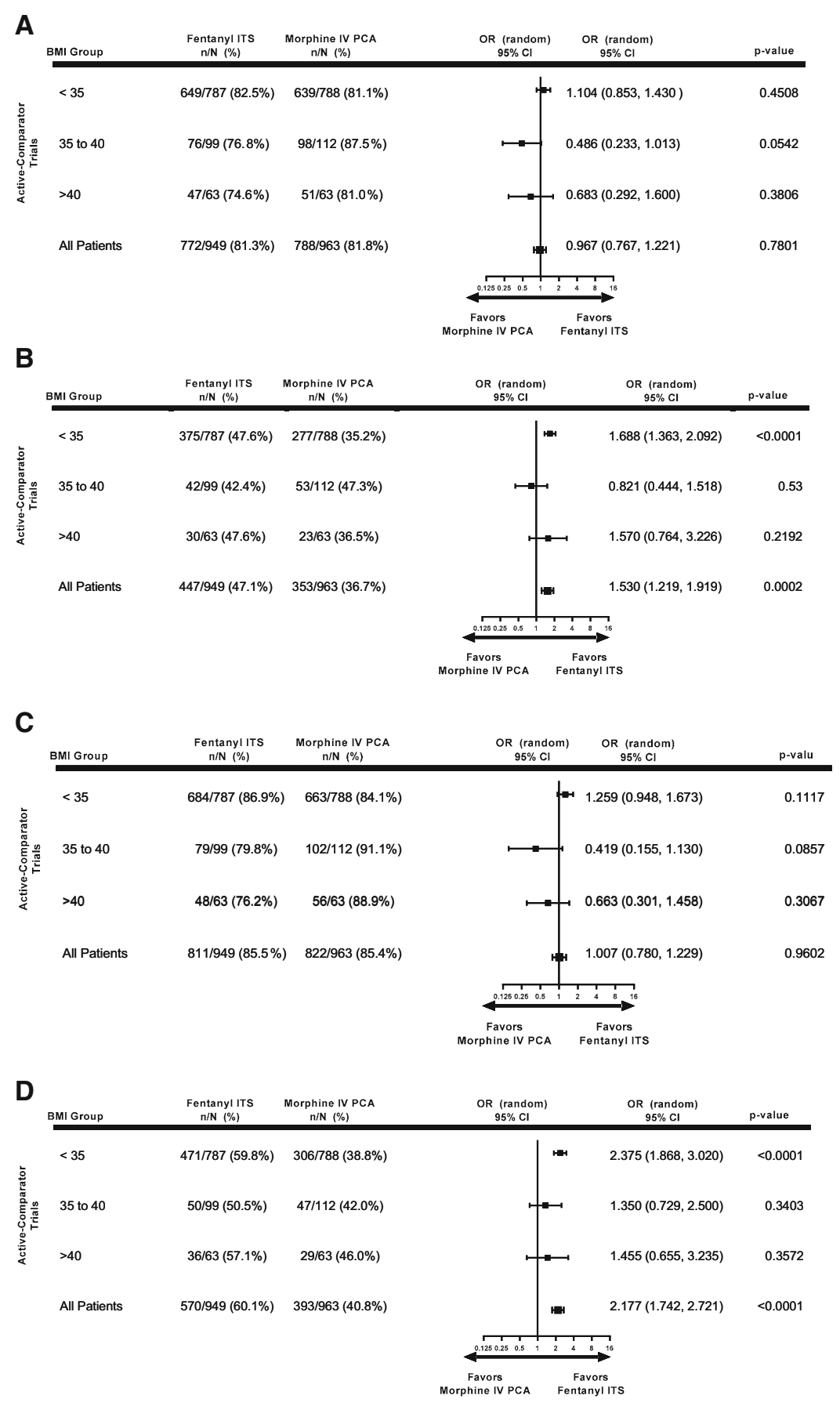

Fig. 1 Patient global assessment of $\mathbf{a}$ success and $\mathbf{b}$ rating of excellent at $24 \mathrm{~h}$. Investigator global assessment of c success and $\mathbf{d}$ rating of excellent at last assessment. $B M I$ body mass index, $C I$ confidence interval, ITS iontophoretic transdermal system, IV PCA intravenous patient-controlled analgesia, $O R$ odds ratio. There are no statistically significant differences in either the PGA or

the IGA between fentanyl ITS and morphine IV PCA when compared by BMI group. The patient global assessment of the method of pain control and the investigator global assessment of the method of pain control are categorical 4-point scales (excellent, good, fair, or poor) with treatment "success" defined as ratings of either excellent or good 


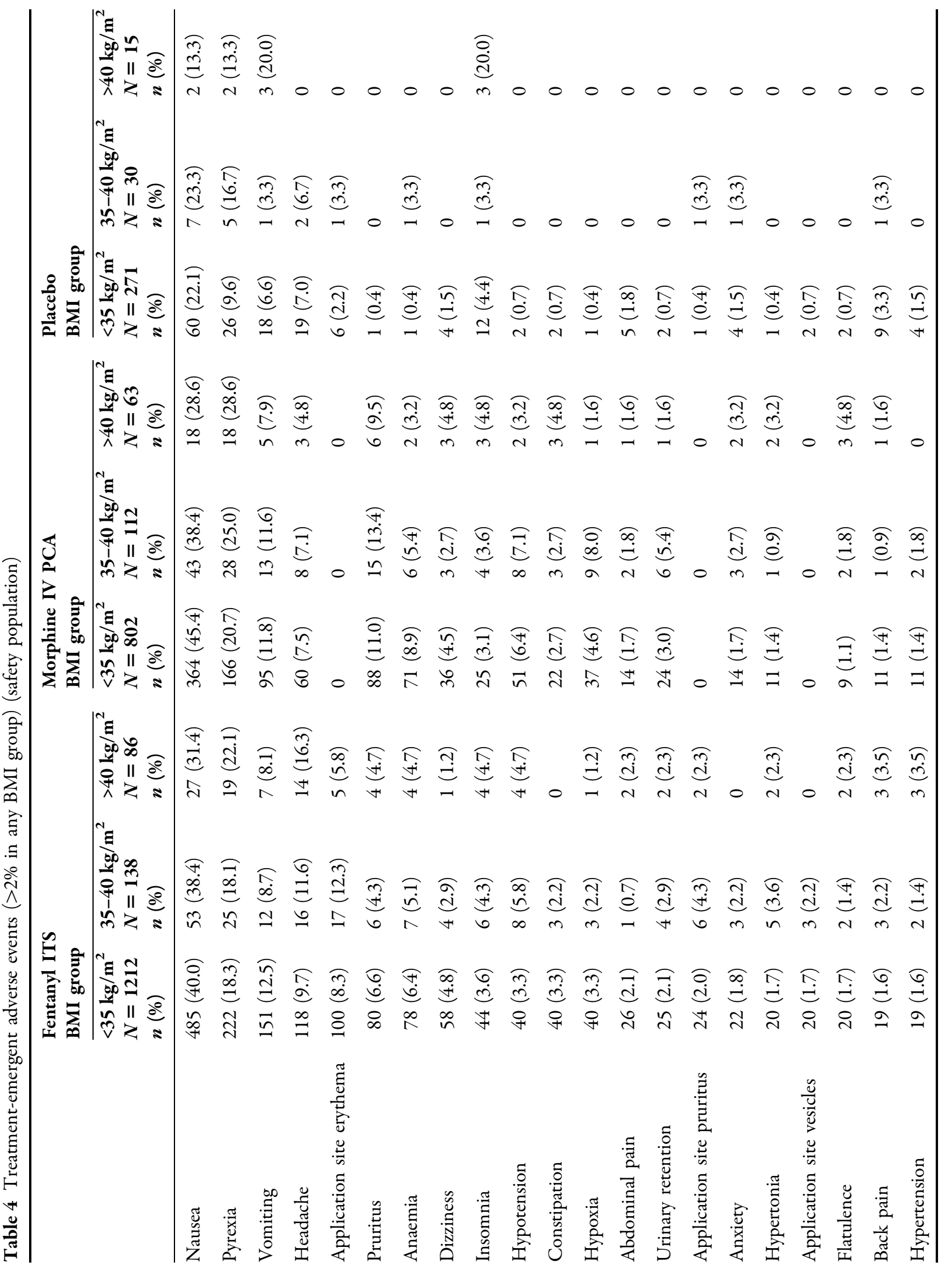




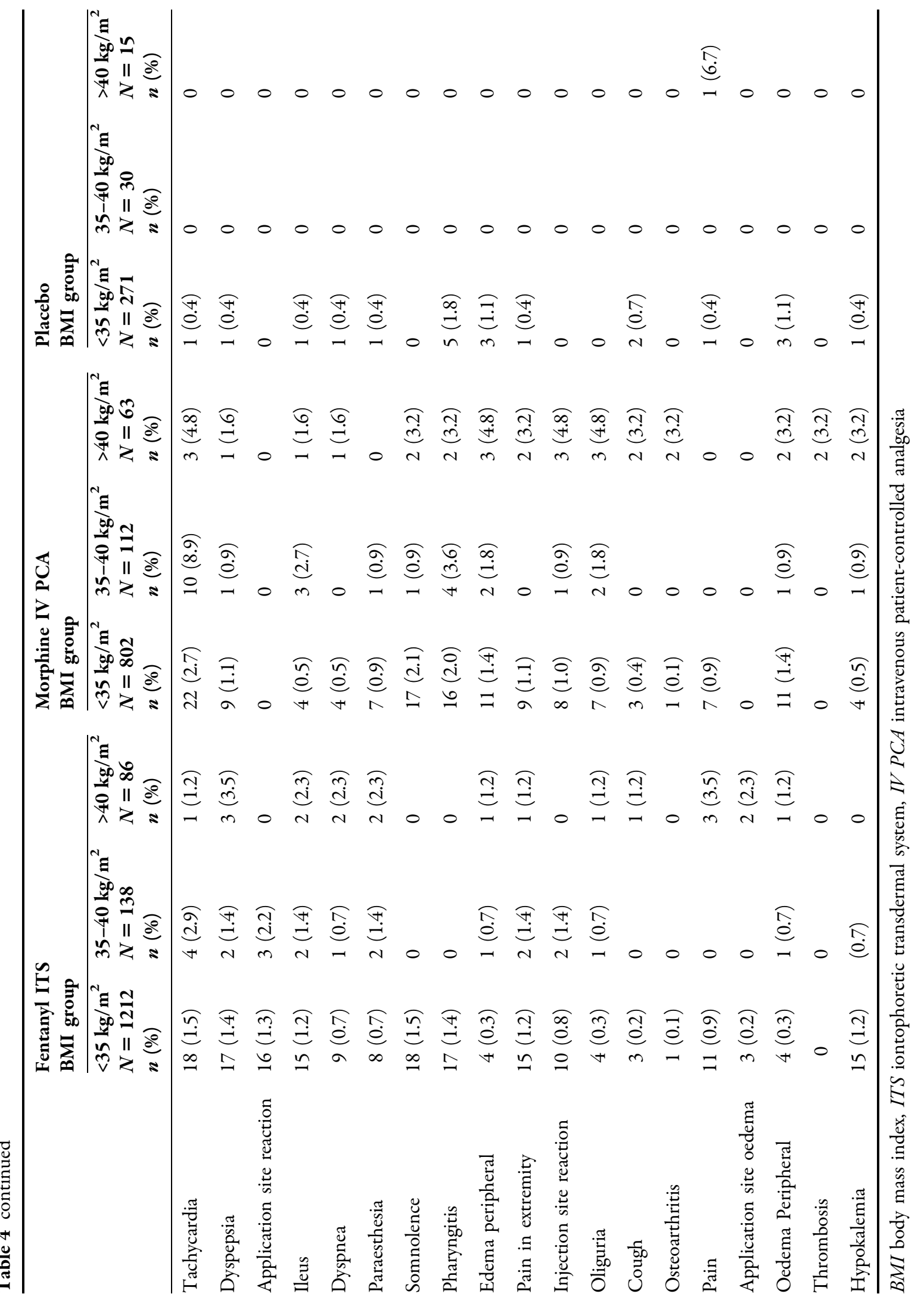




\section{DISCUSSION}

In the controlled studies included in these analyses there were 1436 patients who were treated with fentanyl ITS. These phase 3 studies were designed to be inclusive of a broad range of weights, with no maximum BMI specified in the inclusion/exclusion criteria. The distribution of patients across BMIs was expectedly not even, reflective of the surgical population; however, there were a sizeable number of patients in the higher BMI categories (138 with a BMI $\geq 35 \mathrm{~kg}$ / $\mathrm{m}^{2}$ and $\leq 40 \mathrm{~kg} / \mathrm{m}^{2}$, and 86 with a BMI $>40 \mathrm{~kg} /$ $\mathrm{m}^{2}$ ). Overall, treatment success, as assessed with the PGA of the method of pain control, with fentanyl ITS was $76.5 \%$ in the highest BMI group $\left(>40 \mathrm{~kg} / \mathrm{m}^{2}\right)$ group, which was consistent with the results in the lower BMI categories. Similar results were seen with the IGA. Therefore, it appears that fentanyl ITS is equally effective in the high and low BMI categories. The comparison of fentanyl ITS to morphine IV PCA by each BMI category showed overall consistency between the two treatments as assessed using either the PGA or IGA, further supporting efficacy in high BMI patients.

Fentanyl and morphine are powerful opioids; therefore, it is expected that the pain control is similar between these two modalities (fentanyl ITS and morphine IV PCA). However, the additional benefits of fentanyl ITS relating to the validated instruments of physical therapy ease-of-care [14], nurse ease-of-care [15], and patient ease-of-care [16] have been evaluated and published in other analyses of the full phase 3 dataset. In addition, postoperative mobility is important for every patient undergoing surgery and especially so for obese patients. Early patient mobilization has been shown to reduce the cost of care and improve patient outcomes, whereas immobility is associated with increased complications, length of stays, and costs
[17-19]. Fentanyl ITS is an effective analgesic in the postoperative period and also does not require an IV line and associated equipment (pumps, IV poles). Fentanyl ITS has demonstrated in a double-blind clinical trial that patients find it easier to mobilize when compared to morphine IV PCA [20]. A previous analysis evaluated mobility with fentanyl ITS and morphine IV PCA and found that patients treated with fentanyl ITS were better able to mobilize in the postoperative period than those treated with morphine IV PCA across high and low BMI ranges that were assessed: $<25 \mathrm{~kg} / \mathrm{m}^{2}$; $25 \mathrm{~kg} / \mathrm{m}^{2}$ to $<30 \mathrm{~kg} / \mathrm{m}^{2} ; 30 \mathrm{~kg} / \mathrm{m}^{2}$ to $<40 \mathrm{~kg} / \mathrm{m}^{2}$; and $>40 \mathrm{~kg} / \mathrm{m}^{2}$ [21].

Intravenous access can be challenging to obtain and maintain in obese patients [22]. Notably, patients with poor venous access may experience interruption of standard IV PCA. One of the features of fentanyl ITS is that it reduces the need for a separate IV line for PCA administration in patients and therefore can be advantageous to utilize in the obese patient population.

The mean number of doses of fentanyl ITS utilized in the first $24 \mathrm{~h}$ did not differ between the BMI categories. One research group has previously shown that the $G$ allele of the OPRM1 gene encoding the mu receptor is more common in patients who are obese [23]. This polymorphism has been associated with an increase in the requirement for morphine and fentanyl for pain relief. However, this was not evident in these analyses. Neither fentanyl ITS nor morphine IV PCA showed differences in doses used between the BMI categories. However, it is informative to note that as with other PCA systems, the fentanyl ITS system allows the patient to individualize their pain management regimen; therefore, patients requiring more fentanyl may take up to 80 doses in a 24 -h period and those requiring less can take less. 
Overall, the safety profile was generally similar across the high and low BMI categories. The TEAEs observed most often in the fentanyl ITS group and morphine IV PCA group are common to all opioids and include nausea, pyrexia, vomiting, and headache. Nausea, vomiting, and dizziness were all slightly less common in the BMI $>40 \mathrm{~kg} / \mathrm{m}^{2}$ group compared to the $\mathrm{BMI}<35 \mathrm{~kg} / \mathrm{m}^{2}$ group, while headache was slightly more common in the $>40 \mathrm{~kg} / \mathrm{m}^{2}$ group compared to the BMI $<35 \mathrm{~kg} / \mathrm{m}^{2}$ and the $35-40 \mathrm{~kg} / \mathrm{m}^{2}$ groups.

Respiratory depression is of particular importance in an obese population and needs to be carefully evaluated and monitored when using opioids. In this analysis, in the fentanyl ITS groups, hypoxia was reported in $3.3 \%$ of patients with a BMI $<35 \mathrm{~kg} / \mathrm{m}^{2}$, in $2.2 \%$ of patients with a BMI $\geq 35 \mathrm{~kg} / \mathrm{m}^{2}$ to $\leq 40 \mathrm{~kg} / \mathrm{m}^{2}$, and in $1.2 \%$ of patients with a BMI $>40 \mathrm{~kg} / \mathrm{m}^{2}$. In a meta-analysis that was performed using the active-comparator trials, opioid-related adverse events (including respiratory depression and sedation) were assessed in the aggregate study population [24]. During the development program with more than 2500 patients treated with fentanyl ITS, there were no patients treated with fentanyl ITS who experienced clinically relevant respiratory depression (CRRD), and there were five patients in the morphine IV PCA group who did experience CRRD [25]. However, despite the low rates of CRRD in the clinical studies, it is still important to closely monitor patients being treated with any opioid, including fentanyl ITS, for signs of sedation and respiratory depression. This is especially true for patients who are obese and may be more predisposed to these adverse events.

One limitation of these analyses is that none of the studies were designed to specifically look at BMI and therefore the population is not evenly distributed between the categories. However, this is a reasonably large sample of patients who are obese or morbidly obese. Another limitation is the selection of the BMI categories. These categories were chosen for their clinical relevance to reflect the categories that are commonly used to assess for bariatric surgery eligibility [12]; however, it is reassuring that there was a great deal of consistency across the BMI categories in terms of safety and efficacy. The main purpose of these analyses was to evaluate the safety and efficacy of fentanyl ITS in the high and low BMI categories; however, we also compared the efficacy and safety to morphine IV PCA as there were fairly large sample sizes available from the clinical trial database. Another limitation of these studies, and therefore these analyses, is that they do not factor in multimodal analgesia treatment. It is important to remember that the primary purpose of the studies included was to evaluate the safety and efficacy of fentanyl ITS for regulatory submissions and ultimately drug approval and therefore multimodal analgesia was not included in the methodology. There were some additional endpoints that would have been useful to have measured, such as time to first bowel movement, time to getting up from bed etc.; however, these were not included in the design of the trials and therefore there is no information contained to specifically address these issues within the database. Further research in patients with high BMI using fentanyl ITS in multimodal treatment would be useful to confirm and extend the findings of this paper.

\section{CONCLUSION}

In these analyses, fentanyl ITS was as efficacious, as assessed by the PGA for pain control treatment "success", in patients with high BMI $\left(>40 \mathrm{~kg} / \mathrm{m}^{2}\right)$ as it was for those with 
lower BMIs ( $<35 \mathrm{~kg} / \mathrm{m}^{2}$ or $\left.35-40 \mathrm{~kg} / \mathrm{m}^{2}\right)$ and was generally well tolerated across all BMI categories. Therefore, the results suggest that fentanyl ITS is a valuable option for the short-term treatment of postoperative pain in patients of all BMIs including the obese and morbidly obese.

\section{ACKNOWLEDGEMENTS}

Funding. Sponsorship and the article processing charges for this study were funded by The Medicines Company. All authors had full access to all of the data in this study and take complete responsibility for the integrity of the data and accuracy of the data analysis. The authors wish to acknowledge writing assistance provided by Starr Grundy of SD Scientific, Inc. that was funded by The Medicines Company. All named authors meet the International Committee of Medical Journal Editors (ICMJE) criteria for authorship for this manuscript, take responsibility for the integrity of the work as a whole, and have given final approval to the version to be published.

Disclosures. Eugene R. Viscusi has research funded to his institution by AcelRx, Pacira, Medtronic. He has consulted for AcelRx, The Medicines Company, Mallinckrodt, Cubist, Trevena, Pacira and has received speaking honoraria from AstraZeneca, Mallinckrodt, Cubist, Salix, and Pacira. Li Ding is an employee of The Medicines Company (manufacturer of IONSYS ${ }^{\circledR}$ ). J. Bradley Phipps is an employee of The Medicines Company (manufacturer of IONSYS ${ }^{\circledR}$ ). Loretta M. Itri is an employee of The Medicines Company (manufacturer of IONSYS ${ }^{\circledR}$ ). Philip R. Schauer has no conflicts of interest or financial ties to disclose.
Compliance with Ethics Guidelines. All studies received applicable institutional review board approval prior to initiation. All patients who had participated in the studies provided written informed consent prior to study enrollment. All procedures performed were in accordance with the ethical standards of the institutional and/or national research committee and with the 1964 Declaration of Helsinki, as revised in 2013.

Data availability. The datasets during and/ or analyzed during the current study are available from the corresponding author on reasonable request.

Open Access. This article is distributed under the terms of the Creative Commons Attribution-NonCommercial 4.0 International License (http://creativecommons.org/licenses/ by-nc/4.0/), which permits any noncommercial use, distribution, and reproduction in any medium, provided you give appropriate credit to the original author(s) and the source, provide a link to the Creative Commons license, and indicate if changes were made.

\section{REFERENCES}

1. Ogden CL, Carroll MD, Kit BK, Flegal KM. Prevalence of childhood and adult obesity in the United States, 2011-2012. JAMA. 2014;311(8): 806-14.

2. World Health Organization. Obesity and overweight fact sheet: World Health Organization; 2016. http://www.who.int/mediacentre/factsheets/ fs311/en/. Accessed 18 Aug 2016.

3. American Society of Anesthesiologists Task Force on Acute Pain M. Practice guidelines for acute pain management in the perioperative setting: an updated report by the American Society of Anesthesiologists Task Force on Acute Pain Management. Anesthesiology. 2012;116(2):248-73. 
4. Batheja P, Thakur R, Michniak B. Transdermal iontophoresis. Expert Opin Drug Deliv. 2006;3(1):127-38.

5. Chelly JE, Grass J, Houseman TW, Minkowitz H, Pue A. The safety and efficacy of a fentanyl patient-controlled transdermal system for acute postoperative analgesia: a multicenter, placebo-controlled trial. Anesth Analg. 2004;98(2):427-33.

6. Viscusi ER, Reynolds L, Tait S, Melson T, Atkinson LE. An iontophoretic fentanyl patient-activated analgesic delivery system for postoperative pain: a double-blind, placebo-controlled trial. Anesth Analg. 2006;102(1):188-94.

7. Viscusi ER, Reynolds L, Chung F, Atkinson LE, Khanna S. Patient-controlled transdermal fentanyl hydrochloride vs intravenous morphine pump for postoperative pain: a randomized controlled trial. JAMA. 2004;291(11):1333-41.

8. Hartrick CT, Bourne MH, Gargiulo K, Damaraju CV, Vallow S, Hewitt DJ. Fentanyl iontophoretic transdermal system for acute-pain management after orthopedic surgery: a comparative study with morphine intravenous patient-controlled analgesia. Reg Anesth Pain Med. 2006;31(6):546-54.

9. Minkowitz HS, Rathmell JP, Vallow S, Gargiulo K, Damaraju CV, Hewitt DJ. Efficacy and safety of the fentanyl iontophoretic transdermal system (ITS) and intravenous patient-controlled analgesia (IV PCA) with morphine for pain management following abdominal or pelvic surgery. Pain Med. 2007;8(8):657-68.

10. Grond S, Hall J, Spacek A, Hoppenbrouwers M, Richarz U, Bonnet F. Iontophoretic transdermal system using fentanyl compared with patient-controlled intravenous analgesia using morphine for postoperative pain management. $\mathrm{Br}$ J Anaesth. 2007;98(6):806-15.

11. Rothman M, Vallow S, Damaraju CV, Hewitt DJ. Using the patient global assessment of the method of pain control to assess new analgesic modalities in clinical trials. Curr Med Res Opin. 2009;25(6):1433-43.

12. National Institute of Diabetes and Digestive and Kidney Diseases. Potential candidates of bariatric surgery: US Department of Health and Human Services; 2016. https://www.niddk.nih.gov/healthinformation/health-topics/weight-control/bariatricsurgery/Pages/potential-candidates.aspx. Accessed 7 Sept 2016.

13. Higgins JPT, Green S. Cochrane handbook for systematic reviews of interventions version 5.1.0 2011. www.cochrane-handbook.org. Accessed March 2011.
14. Hartrick CT, Abraham J, Ding L. Ease-of-care from the physical therapists' perspective comparing fentanyl iontophoretic transdermal system versus morphine intravenous patient-controlled analgesia in postoperative pain management. J Comp Eff Res. 2016;5(6):529-37.

15. Lindley P, Ding L, Danesi H, Jones JB. Meta-analysis of the ease-of-care from a patient's perspective comparing fentanyl iontophoretic transdermal system (ITS) versus morphine intravenous patient-controlled analgesia (IV PCA) in postoperative pain management. J Perioper Nurs. 2016. doi:10.1016/j.jopan.2015.11.013.

16. Pestano CR, Lindley P, Ding L, Danesi H, Jones JB. Meta-analysis of the ease-of-care from the nurses' perspective comparing fentanyl iontophoretic transdermal system (ITS) versus morphine intravenous patient-controlled analgesia (IV PCA) in postoperative pain management. J Perioper Nurs. 2016. doi:10.1016/j.jopan.2015.11.012.

17. Delaney CP, Zutshi $M$, Senagore AJ, Remzi FH, Hammel J, Fazio VW. Prospective, randomized, controlled trial between a pathway of controlled rehabilitation with early ambulation and diet and traditional postoperative care after laparotomy and intestinal resection. Dis Colon Rectum. 2003;46(7):851-9.

18. Pashikanti L, Von Ah D. Impact of early mobilization protocol on the medical-surgical inpatient population: an integrated review of literature. Clin Nurse Spec. 2012;26(2):87-94.

19. Kamel HK, Iqbal MA, Mogallapu R, Maas D, Hoffmann RG. Time to ambulation after hip fracture surgery: relation to hospitalization outcomes. J Gerontol A Biol Sci Med Sci. 2003;58(11):1042-5.

20. Langford RM, Chang K-Y, Ding L, Abraham J. Comparison of fentanyl iontophoretic transdermal system and routine care with morphine intravenous patient-controlled analgesia in the management of early postoperative mobilisation: results from a randomised study. $\mathrm{Br} \mathrm{J}$ Pain. 2016;10(4):198-208.

21. Oliasharizi A, Wilson-Byrne T, Shuler FD, Parvizi J. Patient-controlled fentanyl iontophoretic transdermal system (fentanyl ITS) improved postoperative mobility compared to intravenous patient-controlled analgesia (IV PCA) morphine: a pooled analysis of randomized, controlled trials. Pain Practice. 2016. doi:10.1111/papr.12432.

22. Ngui B, McDonald Taylor D, Shill J. Effects of obesity on patient experience in the emergency department. Emerg Med Australas. 2013;25(3):227-32. 
23. Lloret Linares C, Hajj A, Poitou C, et al. Pilot study examining the frequency of several gene polymorphisms involved in morphine pharmacodynamics and pharmacokinetics in a morbidly obese population. Obes Surg. 2011;21(8):1257-64.

24. Sinatra RS, Viscusi ER, Ding L, Danesi H, Jones JB, Grond S. Meta-analysis of the efficacy of the fentanyl iontophoretic transdermal system versus intravenous patient-controlled analgesia in postoperative pain management. Expert Opin Pharmacother. 2015;16(11):1607-13.

25. Hartrick CT, Pestano CR, Ding L, Danesi H, Jones JB. Patient considerations in the use of transdermal iontophoretic fentanyl for acute postoperative pain. J Pain Res. 2016;9:215-22. 